\title{
Giant left atrial appendage aneurysm and atrial fibrillation: chicken or the egg?
}

\author{
Dibbendhu Khanra, ${ }^{1}$ Pradyot Tiwari, ${ }^{\circledR 2}$ Ashwin Kodliwadmath, ${ }^{1}$ Bhanu Duggal ${ }^{1}$
}

${ }^{1}$ Cardiology, All India Institute of Medical Sciences, Rishikesh, Uttarakhand, India

${ }^{2}$ Cardiology, Apex Heart Institute, Ahmedabad, Gujarat, India

\section{Correspondence to Dr Bhanu Duggal, \\ bhanuduggalbmj@gmail.com}

Accepted 10 August 2019

\section{DESCRIPTION}

A 45-year-old woman without history of diabetes mellitus and hypertension presented with episodic palpitation, which is non-exertional, short-lasting and irregular in nature. There is no history suggestive of heart failure, stroke or rheumatic fever in childhood. A 12-lead surface ECG revealed sinus rhythm with normal $P$ wave axis. A 24-hour Holter monitoring revealed paroxysmal atrial fibrillation (AF). A chest radiograph demonstrated cardiomegaly with tented left border (figure 1). Two-dimensional transthoracic echocardiography (2D-TTE) revealed giant left atrial appendage aneurysm (LAAA), almost like a fifth chamber of the heart (figure 2A,B). Spontaneous echo contrast (SEC) was seen swirling inside the LAAA and also in the left atrium (LA) (figure 2A). Also a small sessile thrombus was noted to move to and fro inside the LAAA (figure 2B). Otherwise, 2D-TTE revealed dilated LA, normal valve echo, mild mitral regurgitation and normal left ventricular systolic function. Free blood flow inside and out of the giant LAAA was noted in colour Doppler in systole and diastole, respectively (figure 2C,D). Her P2-CHA2DS2-VASc score (Abnormal P wave axis, Congestive heart failure, Hypertension, Age, Diabetes, Stroke/TIA, VASscular disease

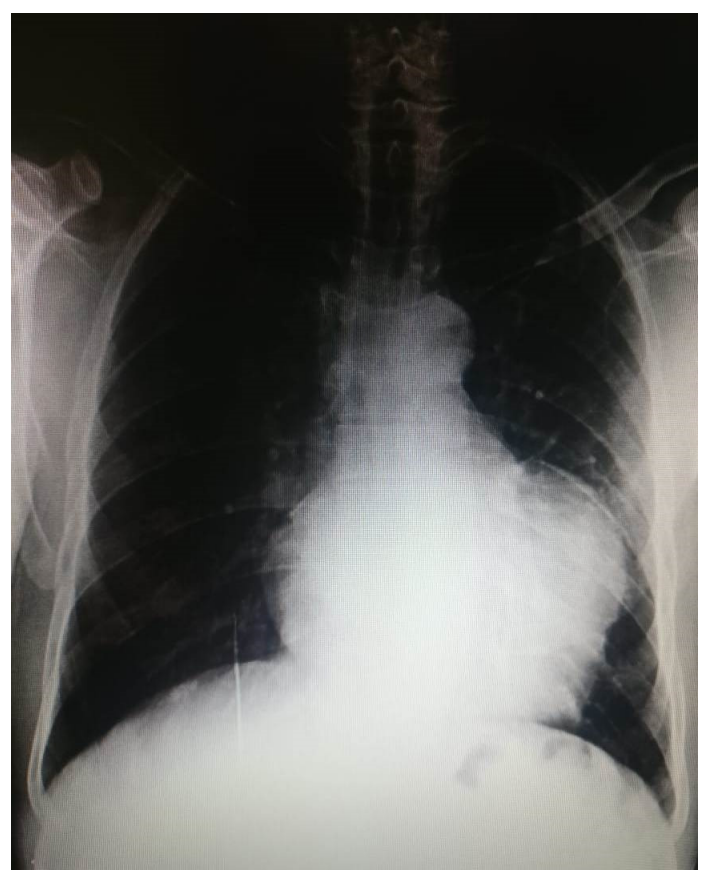

Figure 1 Chest radiograph showing cardiomegaly with large convex bulge beyond the left heart border in the position of the left atrial appendage.
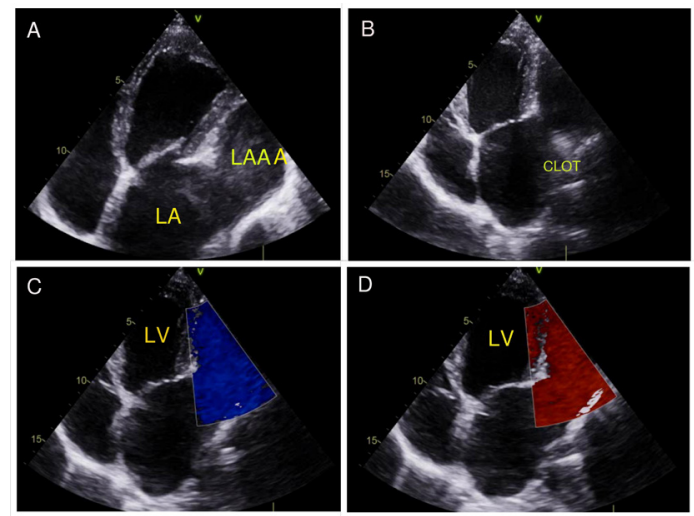

Figure 2 Two-dimensional transthoracic echocardiography revealed giant left atrial appendage aneurysm (LAAA), almost like a fifth chamber of the heart (A-D). Spontaneous echo contrast was seen swirling inside the LAAA and also in the left atrium (LA) (A). Also a small sessile thrombus was noted to move to and fro inside the LAAA (B). Free blood flow inside and out of the giant LAAA was noted in colour Doppler in systole (C) and diastole (D), respectively. LV, left ventricular.

risk score) was $1 .^{1}$ Routine haematological and biochemical parameters were within normal range. Her HAS-BLED score (Hypertension, Abnormal renal/liver function, Stroke, Bleeding, Labile international normalized ratio, Elderly, Drugs/ alcohol risk score) was $0 .{ }^{2}$ She was advised metoprolol succinate extended-release $50 \mathrm{mg}$ once daily to control her palpitation. Dabigatran $150 \mathrm{mg}$ twice daily was started orally to prevent stroke considering the SEC inside the LA and the small thrombus inside the LAAA. Consultation was taken with the heart team, and LAAA closure devices were deemed inappropriate considering the large left atrial appendage (LAA) ostium. ${ }^{3}$ Thus, surgical ligation of the LAAA with removal of the clot was advised, but the patient chose to stay on anticoagulants. The patient is under follow-up for 6 months without any thromboembolic episode.

LAAA is a rare congenital malformation usually discovered incidentally in the third decade, but has also been reported in neonates and children. ${ }^{4}$ Since it was first described by Dimond et $a l^{5}$ on cardiac angiography in 1960, to date approximately 100 such cases have been reported in the literature. ${ }^{6}$ LAAA is often secondarily acquired due to conditions leading to elevated left atrial pressure, including organic mitral valve diseases. ${ }^{6}$ Histopathological finding of fibrosis in the endocardium or myocardium has been noted in both congenital 


\section{Learning points}

Left atrial appendage aneurysm is a rare congenital malformation resulting from dysplasia of the pectinate muscle.

- It can be incidentally discovered on echocardiography or can manifest as atrial fibrillation, thromboembolism or heart failure.

- Management strategy ranges from conservative approach using anticoagulation to surgical approach with aneurysmectomy.

or acquired LAAA. ${ }^{6}$ Rarely, LAAA has been reported to be associated with congenital cardiac abnormalities. ${ }^{6}$

While chest radiograph with large convex bulge beyond the left heart border in the position of the LAA may be suspicious of LAAA, echocardiography can confirm the diagnosis, but it is limited by its small acoustic window. Cardiac CT is the best choice to delineate the structure of the LAAA and its compressive effect on the surrounding structure, however at the cost of radiation. Cardiac MRI has also been reported to diagnose LAAA. ${ }^{7}$

Whereas majority of LAAAs can remain silent, it may complicate into AF, thromboembolism and heart failure due to physical compression of the pulmonary veins, especially among the neonates. ${ }^{8}$ Poor myocardial contractility of the pectinate muscles results in progressive dilation of LAA, which acts as a reservoir chamber, and leads to further dilation and may compress the surrounding structure. ${ }^{8}$ Mild symptoms may be tackled with conservative management including anticoagulants, whereas for compressive symptoms surgical intervention in the form of aneurysmectomy is to be undertaken. ${ }^{8}$

In recent time, understanding of LAA morphology has become important as studies have demonstrated that complex LAA morphology is an independent predictor of AF and stroke. ${ }^{9}{ }^{10}$ In our case, the patient had no risk factors for AF and giant LAAA may be contributing to her AF, as patients with congenital LAAA usually present at an earlier age. ${ }^{4}$ However, non-pulmonary vein AF tends to be persistent, and at early stages of paroxysmal $\mathrm{AF}$ the AF tends to be electrical triggers from the pulmonary veins. ${ }^{11}$ So it is argumentative that LAAA is contributing to AF or not, but the AF can further impair contractility of LAA and may cause progressive dilation of LAAA, leading to further risk of thromboembolism.

Contributors Conception: BD and DK. Case report: PT and AK. Investigations: PT and AK. Discussion: PT and DK. Critical appraisal: BD and DK.

Funding The authors have not declared a specific grant for this research from any funding agency in the public, commercial or not-for-profit sectors.

Competing interests None declared.

Patient consent for publication Obtained.

Provenance and peer review Not commissioned; externally peer reviewed.

\section{REFERENCES}

1 Maheshwari A, Norby FL, Roetker NS, et al. Refining prediction of atrial fibrillationrelated stroke using the P2-CHA2DS2-VASC Score. Circulation 2019;139:180-91.

2 Zhu W, He W, Guo L, et al. The HAS-BLED score for predicting major bleeding risk in anticoagulated patients with atrial fibrillation: a systematic review and meta-analysis. Clin Cardiol 2015;38:555-61.

3 Romero J, Perez IE, Krumerman A, et al. Left atrial appendage closure devices. Clinical Medicine Insights: Cardiology 2014;8:43-52.

4 Aryal MR, Hakim FA, Ghimire S, et al. Left atrial appendage aneurysm: a systematic review of 82 cases. Echocardiography 2014;31:1312-8.

5 Dimond EG, Kittle CF, Voth DW. Extreme hypertrophy of the left atrial appendage: the case of the giant dog ear. Am J Cardiol 1960;5:122-5.

6 Bin Wang B, Li H, Zhang L, et al. Congenital left atrial appendag e aneurysm: A rare case report and literature review. Medicine 2018;97:1-7.

7 Bharati A, Merhcant S, Nagesh C, et al. The "giant dog ear" sign of left atrial appendage aneurysm-revisited on $3 \mathrm{~T}$ cardiac MRI (free-breathing, non-contrast). BJR Case Rep 2016:2:20150292

8 Chen Y, Mou Y, Jiang L-J, et al. Congenital giant left atrial appendage aneurysm: a case report. J Cardiothorac Surg 2017;12:15.

9 Basu-Ray I, Sudhakar D, Schwing G, et al. Complex left atrial appendage morphology is an independent risk factor for cryptogenic ischemic stroke. Front Cardiovasc Med 2018;5:131.

10 Cressa L, Hildick-Smith D, Herrara A, et al. A new practical anatomical classification for left atrial appendage closure. Eurolntervention 2019;15:88-9.

11 Mahida S, Sacher F, Derval N, et al. Science linking pulmonary veins and atrial fibrillation. Arrhythm Electrophysiol Rev 2015;4:40.

Copyright 2019 BMJ Publishing Group. All rights reserved. For permission to reuse any of this content visit

https://www.bmj.com/company/products-services/rights-and-licensing/permissions/

BMJ Case Report Fellows may re-use this article for personal use and teaching without any further permission.

Become a Fellow of BMJ Case Reports today and you can:

- Submit as many cases as you like

- Enjoy fast sympathetic peer review and rapid publication of accepted articles

- Access all the published articles

- Re-use any of the published material for personal use and teaching without further permission

Customer Service

If you have any further queries about your subscription, please contact our customer services team on +44 (0) 2071111105 or via email at support@bmj.com.

Visit casereports.bmj.com for more articles like this and to become a Fellow 